\title{
Costs of delayed dispersal and alloparental care in the fungus-cultivating ambrosia beetle Xyleborus affinis Eichhoff (Scolytinae: Curculionidae)
}

\author{
Peter H. W. Biedermann • Kier D. Klepzig • \\ Michael Taborsky
}

Received: 30 August 2010 /Revised: 14 March 2011 /Accepted: 31 March 2011 /Published online: 15 April 2011

(C) Springer-Verlag 2011

\begin{abstract}
Body reserves may determine the reproductive output of animals, depending on their resource allocation strategy. In insects, an accumulation of reserves for reproduction is often obtained before dispersal by preemergence (or maturation) feeding. This has been assumed to be an important cause of delayed dispersal from the natal nest in scolytine beetles. In the cooperatively breeding ambrosia beetles, this is of special interest because in this group delayed dispersal could serve two alternative purposes: "selfish" maturation feeding or "altruistic" alloparental care. To distinguish between these two possibilities, we have experimentally studied the effect of delayed dispersal on future reproductive output in the xyleborine ambrosia beetle Xyleborus affinis. Females experimentally induced to disperse and delayed dispersing females did not differ in their body condition at dispersal and in their founding success afterwards, which indicates that females disperse independently of condition, and staying adult females are fully mature and would be able to breed.
\end{abstract}

Communicated by N. Wedell

P. H. W. Biedermann $(\bowtie) \cdot$ M. Taborsky

Behavioural Ecology, Institute of Ecology and Evolution,

University of Berne,

Baltzerstrasse 6,

3012 Bern, Switzerland

e-mail: peter.biedermann@iee.unibe.ch

P. H. W. Biedermann · K. D. Klepzig

USDA Forest Service, Southern Research Station,

2500 Shreveport Hwy,

Pineville, LA 71360, USA

K. D. Klepzig

US Forest Service, Southern Research Station,

200 WT Weaver Blvd,

Asheville, NC 28804, USA
However, induced dispersers produced more offspring than delayed dispersers within a test period of 40 days. This suggests that delayed dispersal comes at a cost to females, which may result primarily from alloparental care and leads to a reduced reproductive output. Alternatively, females might have reproduced prior to dispersal. This is unlikely, however, for the majority of dispersing females because of the small numbers of offspring present in the gallery when females dispersed, suggesting that mainly the foundress had reproduced. In addition, "gallery of origin" was a strong predictor of the reproductive success of females, which may reflect variation in the microbial complex transmitted vertically from the natal nest to the daughter colony, or variation of genetic quality. These results have important implications for the understanding of proximate mechanisms selecting for philopatry and alloparental care in highly social ambrosia beetles and other cooperatively breeding arthropods.

Keywords Resource allocation · Capital breeding · Bark beetles $\cdot$ Sociality $\cdot$ Fungus gardening $\cdot$ Cooperative breeding

\section{Introduction}

Living in groups involves three key decisions of totipotent individuals (Helms Cahan et al. 2002): whether or not to disperse (Stacey and Ligon 1991; Kokko and Ekman 2002), whether or not to breed (Keller and Reeve 1994; Hager and Jones 2009) and whether or not to help other group members to raise their offspring (Eden 1987; Stacey and Koenig 1990). Dispersal, as the first and most basal strategic decision, should depend on relative fitness effects of staying and leaving, which are a function of ecological conditions like resource availability, population density and predation risk (Koenig et al. 1992; Heg et al. 2004; 
Bruintjes et al. 2010). Prior to dispersal, however, it is often difficult to estimate potential costs imposed by external factors. Therefore, only internal cues may be available such as body condition (i.e. reserves), or local resource availability.

Studies of the fitness consequences of sociality typically involve highly cooperative vertebrate and insect societies, in which reproduction is restricted to only a few, specialized individuals per group. An ideal model system to unravel the importance of intrinsic factors and external causes selecting for advanced sociality should, however, preferably comprise totipotent individuals that flexibly engage in dispersal, reproduction and helping depending on conditions (e.g. Costa 2006). These requirements are met by the polyphyletic ambrosia beetles, which cultivate ambrosia fungi as food inside galleries excavated in the wood of freshly dead trees (e.g. Schedl 1956; Beaver 1989; Farrell et al. 2001). Dispersal from the natal group in order to find an own gallery is associated with high fitness costs, as suitable wood is patchily distributed and the success rate of establishing a new fungus garden is low (about 20\% in Xyleborinus saxesenii Ratzeburg; Biedermann et al. 2009). Therefore, if fungus productivity in the natal gallery is good and thus optimal feeding conditions prevail, philopatry should be favoured. In fact, such age-dependent, delayed dispersal of scolytine beetles has been witnessed since a long time (e.g. Eichhoff 1881; Whitney 1971; Botterweg 1982; Krausseopatz et al. 1995; McNee et al. 2000). Three non-exclusive hypotheses for this trait have been proposed:

1. Direct fitness benefits through maturation feeding

Delayed dispersal has been associated with preemergence or maturation feeding (Eichhoff 1881; Botterweg 1982; McNee et al. 2000). Evidence for maturation feeding exists from phloem-feeding mountain pine beetles, where females were experimentally prevented from feeding after eclosion. They matured normally but were less likely to breed successfully and laid smaller eggs (Elkin and Reid 2005). Scolytine ambrosia beetles, however, have a different feeding habit, using ambrosia fungi as their sole nutritional source. Female ambrosia beetles were found to lay eggs only after growing their own fungus garden on which they fed (French and Roeper 1975; Kingsolver and Norris 1977; Roeper et al. 1980; Beaver 1986). Hence, it is presently unclear whether reserves accumulated before emergence will raise the productivity of those beetles sufficiently to outweigh the fitness costs of delayed dispersal.

2. Indirect fitness benefits through cooperative brood care

Females delaying dispersal could help to raise siblings, especially since the fungus cultivation of ambrosia beetles may benefit from the cooperation of several individuals (Kirkendall et al. 1997; Mueller et al. 2005). Evidence for such cooperative brood care exists in $X$. saxesenii, where the number of larvae and pupae is proportional to the number of adult female helpers in a gallery (Peer and Taborsky 2007), and behavioural observations revealed cooperative care (Biedermann 2007; Biedermann et al. 2009). If females dispose of the potential to help raising broods but suffer from limited fertility, they may benefit by caring for the brood of relatives instead of taking the risk to disperse and breed independently (West-Eberhard 1975; Craig 1983; Roisin 1994).

3. Direct fitness benefits through reproduction in the natal gallery

Staying adult daughters might also reproduce in the natal gallery. This was observed in $X$. saxesenii, where one quarter of the females were found to lay eggs in their natal nest (Biedermann 2007).

In our study species, Xyleborus affinis Eichhoff (Xyleborini, Scolytinae), daughters flexibly disperse over a period of about 50 days. Prior to dispersal, all females cooperatively care for the brood and fungal cultures in their natal, commonly defended gallery for at least 1 week (Roeper et al. 1980). Here we aim to unravel whether prolonged philopatry of females causes costs or benefits regarding body condition and future reproductive success, i.e. to distinguish between hypothesis (1) and the two alternatives ( 2 and 3 ) above. To this end, we experimentally induced dispersal of adult females and measured their body weight, size and reproductive success in comparison to a control group that was allowed to disperse deliberately without experimental interference. If maturation feeding occurred, induced dispersers should be less successful in gallery foundation and offspring production than voluntarily delayed dispersers (hypothesis 1) because the former had stayed shorter in the natal gallery than the latter before experimental collection. If in contrast induced dispersers are more successful, this would reveal that delayed dispersal is associated with a reduction in body condition, indicating fitness costs by cooperative brood care (hypothesis 2) or reproduction prior to dispersal (hypothesis 3 ). The latter possibility we checked by counting offspring numbers at the time of collection and by determining the ovarian status of all collected females.

\section{Material and methods}

Study species

$X$. affinis is a tropical and subtropical member of the scolytine subtribe Xyleborini, which are characterized by 
haplodiploidy, strongly female-biased sex ratios ( $X$. affinis: 1:8.5 males/females-Roeper et al. 1980; 1:15.2 males/ females-Biedermann, unpublished data) and matings between full siblings in their natal gallery (Xylosandrus germanus: Peer and Taborsky 2004, 2005). Only female beetles disperse from their host trees by flight. They transmit spores of species-specific ambrosia fungi to the new gallery in a spore carrying organ ("mycetangium"; Francke-Grosmann 1956), or in some cases in the hindgut (Francke-Grosmann 1975). X. affinis galleries deeply penetrate the wood of deciduous trees with single tunnels extending over $6 \mathrm{~m}$ that may be inhabited by several generations for up to 4 years (Schneider 1987). Under laboratory conditions, two to three generations may develop within a gallery, which will host up to 100 individuals of all developmental stages concurrently (Biedermann et al. 2009; Biedermann, personal observation).

Preparation of artificial medium

We filled sterile glass tubes $(18 \mathrm{~mm}$ diameter $\times 150 \mathrm{~mm}$ length; Bellco Glass, Vineland, NJ, USA) with standard medium which consists of $0.35 \mathrm{~g}$ streptomycin, $1 \mathrm{~g}$ Wesson's salt mixture, $5 \mathrm{~g}$ yeast, $5 \mathrm{~g}$ casein, $5 \mathrm{~g}$ starch, $10 \mathrm{~g}$ sucrose, $20 \mathrm{~g}$ agar and $75 \mathrm{~g}$ oak tree sawdust (Biedermann et al. 2009). All ingredients were mixed and supplemented by $2.5 \mathrm{ml}$ of wheat germ oil, $5 \mathrm{ml} \mathrm{95 \%} \mathrm{ethanol} \mathrm{and} 500 \mathrm{ml}$ of deionised water. The mixture was autoclaved for $20 \mathrm{~min}$ at $124^{\circ} \mathrm{C}$ and covered immediately with sterile plastic caps (Bellco Glass kap-uts, Vineland, NJ, USA). After the medium had cooled down, we scratched its surface with a sterile scalpel to facilitate the onset of tunnel excavation by a founder female. Then we closed the tubes again with the plastic caps and left them to set for 4 to 5 days.

\section{Laboratory rearing of the beetles}

All females used in this study were descendants of the first laboratory generation of females collected from oak $\operatorname{logs}$ in Pineville, LA, USA (123 ft asl; $\left.31^{\circ} 20^{\prime}, 92^{\circ} 24^{\prime}\right)$ in summer 2007. Dispersing females emerged from their natal gallery on the surface of the artificial medium and were collected for rearing of consecutive laboratory generations (Biedermann et al. 2009). Before starting a new gallery, females were surface-sterilized by washing them first for a few seconds with $95 \%$ ethanol and then with deionised water. Then each female was placed singly on the prepared medium in a separate glass tube. These tubes were reclosed with the caps and stored at room temperature $\left(\sim 23^{\circ} \mathrm{C}\right)$ in darkness (wrapped in paper, but light could shine on the entrance).

Following insertion on the medium, females immediately started to bore a tunnel. As they penetrate the medium, they inoculate the tunnel walls with ambrosia fungus spores from their mycetangia, which results in a fungus layer lining the tunnel walls within a week after insertion (Roeper et al. 1980). At that time, females start to produce eggs, while feeding on fungus providing the essential nutrients (Kingsolver and Norris 1977). The progeny passes through three larval instars and a pupal stage. After eclosion, it takes a few days until the beetles fully sclerotize. The first adult offspring appear in the tunnels around 38 days after gallery foundation. The first daughters start to disperse around day 50 after gallery foundation, but most of them delay dispersal from their natal nest for much longer. Daughters generally delay their dispersal: (1) The first developing female offspring stay on average for 12 days after full sclerotization before they start to disperse (Fig. 1; see also Roeper et al. 1980); (2) also after dispersal has started, females accumulate in the gallery as the rate of females eclosing from the pupal stage is higher than the dispersal rate. About 80-90 days from gallery foundation, the medium deteriorates, which is when production of new progeny has ceased and all individuals leave the gallery (Fig. 1).

\section{Experimental manipulations}

We observed seven galleries of the second laboratory generation during days 57-63 after gallery foundation and immediately collected the first females emerging on the surface of the medium to disperse (henceforth called delayed dispersers; Fig. 1). On the same day, we dissected each of these galleries and collected the same number of mature females (fully sclerotized) from the

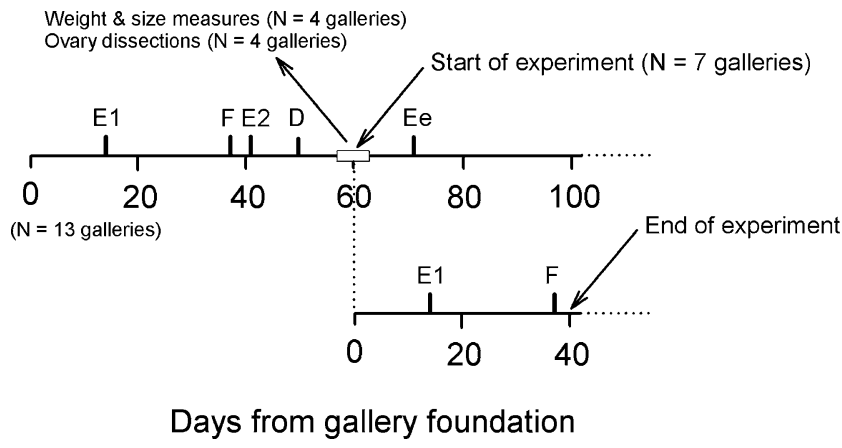

Fig. 1 Typical phenology of a laboratory gallery in $X$. affinis and the timing of our manipulations. E1 start of egg laying of the founder female, $F$ first full sclerotization of a daughter, E2 start of daughter egg laying, while the foundress usually continues to lay eggs, $D$ first daughters start to disperse from gallery, $E e$ end of egg laying because of deterioration of the medium. We collected dispersing and staying females between days 57 and 63, either to take measurements (dry weight, body length, ovary development) or to let them breed independently for 40 days until we dissected the daughter galleries to count their offspring 
same gallery as had emerged on the surface (henceforth called induced dispersers). Thus, we sampled two to 24 females per gallery, resulting in a total of 38 induced and 37 delayed dispersing females (one delayed disperser died during handling). All delayed and induced dispersers were then inserted singly into new tubes to find their own galleries. Forty days later, we opened all galleries, checked whether a brood had been produced and counted offspring numbers. In the analyses of treatment effects on offspring numbers, we excluded females that did not produce any offspring $(N=11)$ and one family where only one induced dispersing female reproduced at all (so no comparison with a sibling delayed dispersing female was possible).

Measurements of delayed and induced dispersing females

At the time we started our experimental manipulations, we also dissected eight galleries and stored all dispersing and staying females (equivalent to the delayed and induced dispersing females) in $95 \%$ ethanol. At a later date, we dry-weighed all females from four of these galleries with a high-precision scale (precision $0.01 \mathrm{mg}$; Sartorius ME215S-OCE, Göttingen, Germany) after a 24-h drying process (oven, $80^{\circ} \mathrm{C}$ ). We measured their body length to the nearest $0.01 \mathrm{~mm}$ using a microscope $(\times 6.4-\times 40$ magnification $)$ with an ocular micrometer. Using the same microscope, we also dissected the ovaries of all females from the remaining four galleries from the dorsal side with high-precision tweezers. We classified ovaries as either immature (ovaries rudimentarily developed), mature (fully developed ovaries but no oocytes) or egg carrying (four ovarioles containing one or more oocytes; see figures in Fischer 1954).

\section{Statistical analyses}

Our nested design with variable numbers of repeated measures from the experimental galleries generated matched, non-independent measurements. Linear mixed models may be used when the distribution of the repeated responses for a subject has a multivariate normal distribution. This is unlikely when the dependent variable is binary or count data (Norusis 2007). Therefore, generalized estimating equations (GEE), which are an extension of generalized linear models, were used to analyse effects of dependent variables on correlated binary or count response variables (Liang and Zeger 1986; Zeger and Liang 1986). We used GEEs with an exchangeable correlation structure of the response variable within a cluster (= gallery identity) to identify effects of our treatment (induced vs. delayed dispersing females) on (1) the ability to found a gallery successfully by using binomial error distributions and (2) the offspring numbers (numbers of eggs, larvae, pupae and adults) by using normal error distributions. In a GEE model, the correlation structure of the non-independent measurements (i.e. the influence of gallery identity) is modelled separately and is not of primary interest. However, as breeding success and productivity appeared to be highly variable between progeny of different galleries, we additionally analysed the effects of gallery of origin. We used gallery of origin as the sole explanatory variable in a logistic regression (LR) to determine its influence on breeding success and in a general linear model (GLM) to determine its influence on productivity. Another GEE model was performed to analyse dry weight differences between delayed and induced dispersing females. Statistical analyses were performed with SPSS (Version 15.0, (C) SPSS Inc., Chicago, IL, USA, 1989-2005) and R (R Development Core Team 2008). Model coefficients are reported as $B \pm$ standard error of the estimate (SE) throughout, with the induced dispersers as the reference category (coefficient set to zero). Significance level $\alpha=0.05$.

\section{Results}

\section{Experimental manipulations}

Of the 75 experimental foundresses, 64 produced a brood successfully. Treatment did not affect whether a brood was successfully produced or not (seven of 37 delayed dispersing females vs. four of 38 induced dispersing females failed to produce a brood; GEE: $B \pm$ SE $0.653 \pm$ $0.546, \chi^{2}=1.429, d f=1, P=0.232$ ), and there was no effect of gallery identity on founding success (LR: $\chi^{2}=0.001, d f=1$, $P=0.97, N=75$ ).

Of the 64 successful foundresses, induced dispersers produced more offspring than delayed dispersers (GEE: $B \pm$ SE 9.137 $\pm 4.426, \chi^{2}=4.263, d f=1, P=0.039$ ), which rejects the maturation feeding hypothesis. This relationship was observed in four out of six galleries (Fig. 2a). If the total offspring numbers were split up between different developmental stages, it became clear that this result was solely caused by the variance in the numbers of laid eggs (GEE: $B \pm$ SE 5.175 $\pm 1.6, \chi^{2}=10.466, d f=1, P=0.001$ ), but not by the numbers of larvae (GEE: $B \pm$ SE $4.263 \pm 3.797, \chi^{2}=1.26, d f=$ 1, $P=0.262$ ), pupae (GEE: $B \pm$ SE $2.756 \pm 2.589, \chi^{2}=1.133$, $d f=1, P=0.287$ ) and adults (GEE: $B \pm \mathrm{SE} 2.703 \pm 3.492$, $\left.\chi^{2}=0.599, d f=1, P=0.439\right)$ present 40 days after the treatment (Fig. 2b). This difference in egg numbers is not 


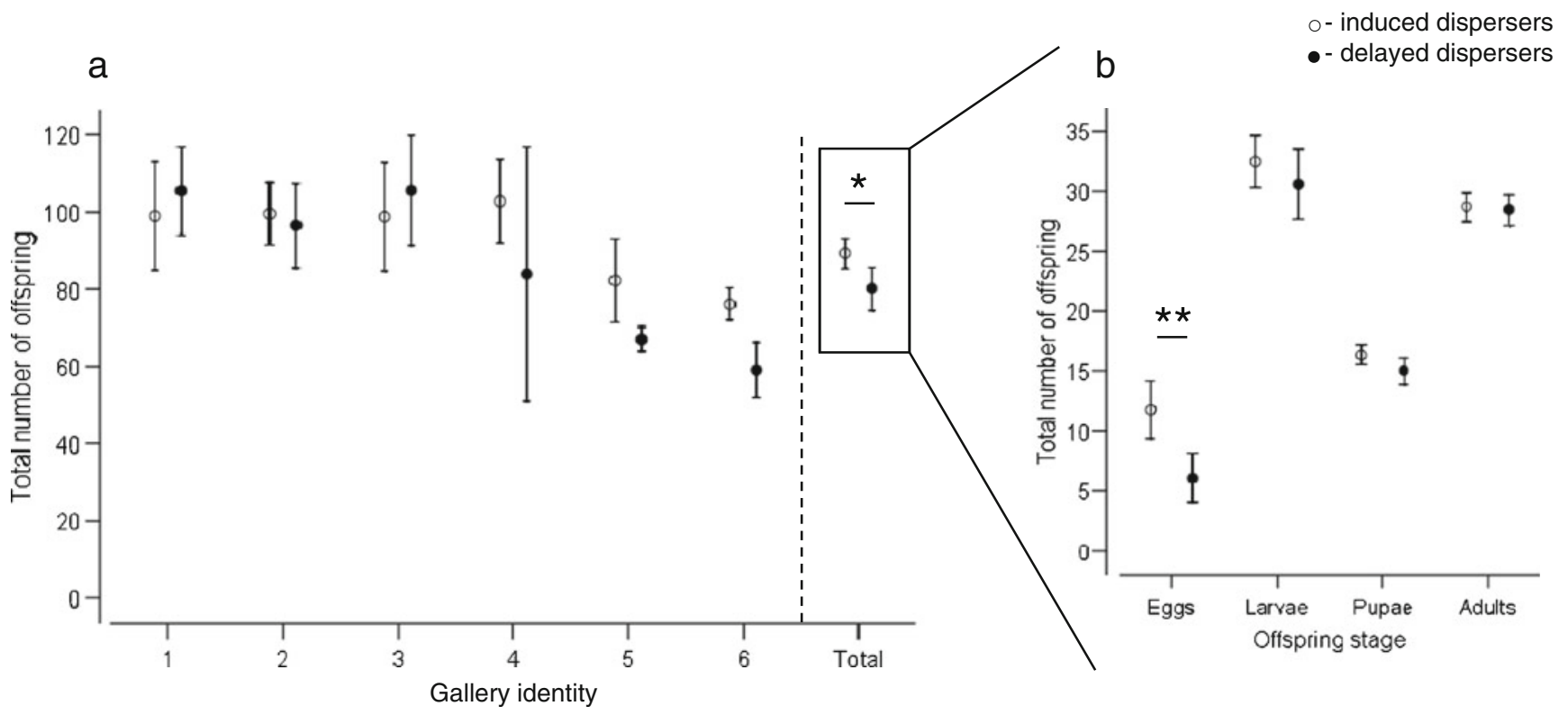

Fig. 2 Comparison of total numbers of offspring produced by the two experimental groups of females 40 days after the treatment. a Offspring numbers in dependence of the gallery of origin and the overall total. Numbers of daughter galleries included (induced dispersers/delayed dispersers): gallery ${ }_{1}(2 / 2), \mathrm{g}_{2}(5 / 6), \mathrm{g}_{3}(5 / 5), \mathrm{g}_{4}$ $(5 / 2), g_{5}(4 / 4)$ and $g_{6}(12 / 11) ; g_{7}$ was omitted because only one female of this gallery reproduced successfully. $\mathbf{b}$ The overall total is split up

an artefact from a few galleries, since we found the mean egg numbers to be higher in the induced dispersers than in the delayed dispersers in all six galleries analysed (Fig. 3 in the "Appendix"). The total number of offspring produced by successful foundresses was strongly affected by the gallery of origin (GLM: $\left.F_{5,63}=5.6, P<0.001\right)$.

Measurements of delayed and induced dispersing females

Body length and weight did not differ significantly between induced $(\bar{x}=2.85 \mathrm{~mm}, \mathrm{SE}<0.01 ; \bar{x}=0.41 \mathrm{mg}$, $\mathrm{SE}=0.01, N=31)$ and delayed dispersing females $(\bar{x}=2.85 \mathrm{~mm}, \mathrm{SE}<0.01 ; \bar{x}=0.4 \mathrm{mg}, \mathrm{SE}=0.02, N=13$; GEE body length: no variability, $P>0.05$; GEE body weight: $B \pm$ SE $-0.03 \pm 0.52, \chi^{2}=-0.06, d f=1, P=0.95$; see Fig. 4 in the "Appendix").

About $24 \%$ of the induced dispersing females had ovaries containing eggs (14 of 59 adult females from four galleries; Table 1), which suggests that staying females often produce eggs in their natal gallery. The number of delayed dispersers was independent of the number of staying females (= induced dispersers; Spearman: $R=-0.32, P=0.68)$ and of the number of females among them laying eggs (Spearman: $R=-0.21, P=$ $0.79, N=4$ galleries). The likelihood to breed differed between galleries (Fisher's exact test: $P=0.03, N=59$ ). Delayed in the four developmental offspring stages. The differences between the numbers of eggs, larvae and pupae reflect the average duration of these stages (for $X$. saxesenii: egg stage -5 days (range $=5$ ), three larval instars -11 days (range $=8-21$ ), pupal stage -7 days $($ range $=6-7$ ); Biedermann et al. 2009). Arithmetic means of daughter gallery offspring numbers are shown with their standard errors. GEE: $* P<$ $0.05 ; * * P<0.001$

dispersing females never had eggs in their ovaries (14 adult females from four galleries).

\section{Discussion}

The first developing female offspring in all $X$. affinis galleries stayed and helped in brood care for at least

Table 1 Developmental status of the ovary of delayed and induced dispersing females in four dissected galleries

\begin{tabular}{lllllll}
\hline & $\begin{array}{l}\text { Ovary } \\
\text { development }\end{array}$ & \multicolumn{3}{l}{ Gallery } & \multicolumn{3}{c}{ Total (\%) } \\
\cline { 3 - 6 } & & $\mathrm{A}$ & $\mathrm{B}$ & $\mathrm{C}$ & $\mathrm{D}$ & \\
\hline Delayed dispersers & Immature & 0 & 1 & 8 & 0 & 64.3 \\
& Mature & 2 & 0 & 0 & 3 & 35.7 \\
& Egg carrying & 0 & 0 & 0 & 0 & 0 \\
& Total & 2 & 1 & 8 & 3 & 100 \\
Induced dispersers & Immature & 2 & 2 & 3 & 13 & 33.9 \\
& Mature & 6 & 2 & 1 & 16 & 42.4 \\
& Egg carrying & 1 & 5 & 3 & 5 & 23.7 \\
& Total & 9 & 9 & 7 & 34 & 100 \\
\hline
\end{tabular}


1 week (cf. Roeper et al. 1980) and on average for 12 days after full sclerotization before they started to disperse (Fig. 1). Also after dispersal has started, the rate of female eclosion from the pupal stage is higher than the dispersal rate, which causes females to accumulate in the gallery. This suggests that females usually delay dispersal, probably in order to help in care of the brood produced by the foundress (i.e. their mother) or later on potentially also by sisters.

Given that females delay their dispersal, our data reject the predictions of the maturation feeding hypothesis. In contrast, the predictions of the other two hypotheses were confirmed: Delayed dispersal seems to entail long-term costs, most likely by the investment in cooperative care, and some females reproduce in their natal gallery. The data reveal also that philopatric females are fully capable to found an own gallery and to start reproducing at any point of time, disproving the assumption that they are infertile before dispersal (Graham 1961). Hitherto, prolonged philopatry, which is a common feature of female life histories in many phloem (e.g. Kirkendall et al. 1997) and ambrosia feeding Scolytinae (e.g. Kalshoven 1962; Peer and Taborsky 2007; Biedermann et al. 2009), has been attributed usually to maturation feeding (Eichhoff 1881; Botterweg 1982; McNee et al. 2000). In contrast, our findings indicate that in $X$. affinis other benefits select for philopatry. Firstly, philopatry can raise the inclusive fitness of females by enhancing the production of close relatives (Bischoff 2004; Biedermann 2007; Peer and Taborsky 2007). Galleries with more adult females produced more offspring in the closely related species $X$. saxesenii (Peer and Taborsky 2007), also over multiple generations (Biedermvann et al. 2009). Direct observations of $X$. affinis and other xyleborine species revealed that staying adult females share in brood care and fungus maintenance (Roeper et al. 1980; Bischoff 2004; Biedermann 2007; Biedermann et al. 2009). The members of a gallery are almost clones due to mating occurring virtually exclusively among full siblings (for $X$. germanus: sib-mating estimate $=97 \%$ of matings, Keller et al., submitted for publication; see also Peer and Taborsky 2005). Secondly, direct fitness benefits can apply for females that reproduce at home, which was true for nearly a quarter of staying females in our sample. This is a similar proportion as observed in X. saxesenii (Biedermann 2007).

There might be alternative causes to costly helping for the lowered productivity of delayed dispersers: (1) The reduced post-dispersal productivity of females may have resulted from their own egg laying in the natal gallery. However, it is unlikely that this would fully explain the productivity differences found between the two groups of females as the total numbers of eggs, larvae, pupae and teneral beetles present in the galleries in relation to the total number of adult females were very small at the time of our treatment (day 60: mean $=$ $2.57, \mathrm{SE}=1.15$, range $=0-8, N=7$ galleries), suggesting that there was only very sparse egg laying, if any, by females other than the foundress. (2) The delayed dispersing females may have developed flight muscles for dispersal which the induced dispersers might have lacked; the reuse of energy when transferring nutrients from flight muscles to ovaries may bring about extra synthesis costs (Zera and Denno 1997), which could affect productivity (e.g. Elkin and Reid 2005). This possibility needs to be scrutinised in future studies focusing on the energetics of dispersal, reproduction and reorganisation of tissue in these beetles.

Independently of whether females might benefit from staying by raising their inclusive or direct fitness, dispersal, by contrast, is costly due to high mortality risk (Milne and Giese 1970; Dahlsten 1982). In addition, establishing a fungus culture after dispersal fails very often (only $20 \%$ of founded fungus gardens are successful in $X$. saxesenii; Peer and Taborsky 2007; Biedermann et al. 2009). Therefore, it is conceivable that females might compete for staying in a productive nest (Kokko and Ekman 2002). If this was the case, dispersing females could be the less competitive individuals, which might explain why they were less successful in their breeding attempts after dispersal when compared to philopatric females. However, two results indicate that competition for staying does not occur or has little effect on dispersal in $X$. affinis. First, we found no difference in size or body condition between dispersing and staying females. Second, the numbers of females present in the gallery (including egg layers and non-reproductives) did not relate to the numbers of dispersers in our experiment. A relationship between female density and dispersal would be expected, however, if competition triggers dispersal, regardless whether dispersal occurs voluntarily or is forced by other colony members.

Delayed dispersing females differed in their ovary development from those collected in the gallery, as egg-carrying ovaries were only found among the latter. This might suggest two different reproductive strategies of females: (1) A dispersal phenotype showing delayed ovary maturation and perhaps also a strongly developed flight apparatus and (2) a philopatric phenotype that stays, helps in brood care and eventually breeds in the natal gallery. Such strategies are common in insects because there is often a trade-off between 
construction of the flight apparatus and ovary development (Zera and Denno 1997). Nevertheless, the existence of two distinct phenotypes is yet unknown from scolytine beetles, and we also do not find evidence for this possibility in our data. First, we did not find any differences in body size and weight, which contrasts with theoretical predictions that dispersers should be the stronger competitors under kin competition (Gyllenberg et al. 2008; Bonte and De La Pena 2009); this has been confirmed also in several vertebrate (e.g. Kawata 1987; Cote et al. 2007) and insect taxa (e.g. Sundstrom 1995; Moore et al. 2006). Body condition is an important factor determining successful host finding and gallery foundation in scolytine beetles (Dendroctonus ponderosae; Latty and Reid 2010). Second, selection for fixed behavioural strategies, which would be associated with a dispersal polymorphism, is probably weak for Scolytinae because of their unpredictable environmental conditions. Indeed, there is a multitude of studies showing their enormous flexibility to react adaptively to changing environmental conditions, for example, by transferring nutrients between flight muscles and ovaries back and forth within a few days (e.g. Reid 1958; McNee et al. 2000). This might explain why both female groups showed the same founding success and about the same timing of first egg laying (reflected by the equal number of adult offspring in both treatments), which would be unlikely assuming two distinct phenotypes. In summary, although there is variation in reproductive success and probably flight performance, dispersal and philopatry are likely rather plastic, conditiondependent strategies which are predicted to be superior to fixed strategies in many cases (e.g. Ims and Hjermann 2001; Bowler and Benton 2005).

"Gallery of origin" significantly affected both the number of offspring produced after dispersal and the number of egg layers among staying females. It has been suggested that the mutualistic microbial complex (certain fungi and bacteria) maintained in the gallery is the major factor influencing gallery productivity via the quality of the transmitted mutualistic microbes (Baker and Norris 1968; Kok et al. 1970; Kingsolver and Norris 1977; Batra 1979; Kajimura and Hijii 1994). The beetles' genetic quality might be another factor that has not yet been explored. Unfortunately, our approach does not allow distinguishing between these two potential causes of the observed gallery effects.

Xyleborine ambrosia beetles live under the very conditions where higher sociality has probably evolved multiple times (Hamilton 1978), which includes high levels of inbreeding, protection of a common nest and a virtually unlimited food source (e.g. some hymenoptera, gall-thrips, aphids and lower termites: Choe and Crespi 1997; Korb and Heinze 2008). Therefore, this group can provide insights into intrinsic and ecological factors inducing individuals to stay at home rather than to disperse and to help rather than to reproduce independently, which are basic components of social evolution.

Acknowledgements We are grateful to Stacy Blomqvist and Eric Ott for collecting $X$. affinis in the field and starting the first lab galleries. This manuscript benefitted greatly from comments of Tabea Turrini, Dik Heg and two anonymous reviewers. The study was supported by a cooperative agreement between the Department of Behavioral Ecology, University of Bern and the Southern Research Station, USDA Forest Service. PHWB is a recipient of a DOC fellowship of the Austrian Academy of Sciences at the Department of Behavioural Ecology, University of Bern, and was partly funded by a fellowship of the Roche Research Foundation.

\section{Appendix}

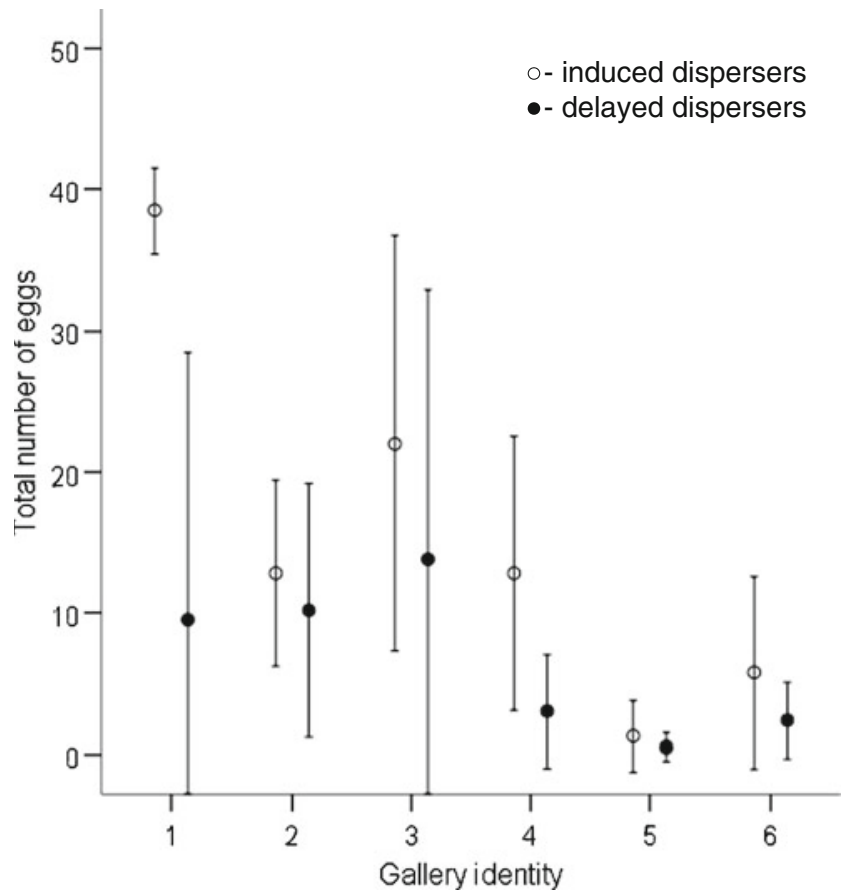

Fig. 3 Total numbers of eggs produced by the two experimental groups of females 40 days after the treatment. Induced dispersers laid more eggs than delayed dispersers overall (GEE: $P<0.001$ ). Numbers of daughter galleries included (induced dispersers/delayed dispersers): gallery $_{1}(2 / 2), \mathrm{g}_{2}(5 / 6), \mathrm{g}_{3}(5 / 5), \mathrm{g}_{4}(5 / 2), \mathrm{g}_{5}(4 / 4)$ and $\mathrm{g}_{6}(12 / 11)$. Arithmetic means are shown with their standard errors 


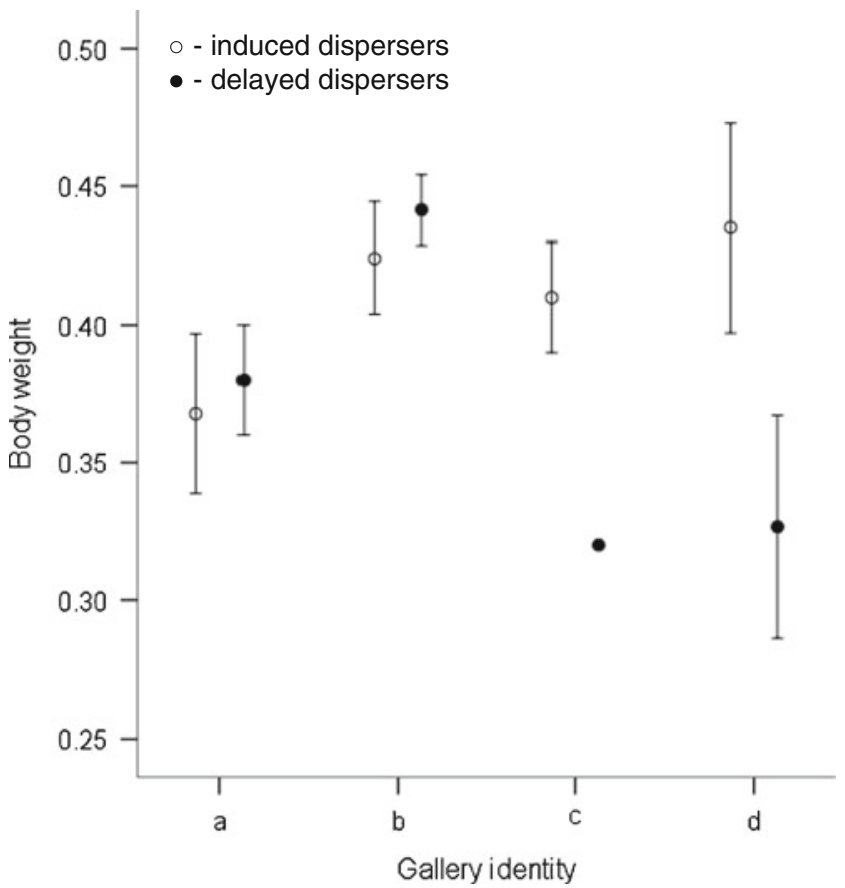

Fig. 4 Comparison of the body weight $(\mathrm{mg})$ of females from the two experimental groups collected in four galleries. There was no significant difference between induced and delayed dispersers (GEE: $P=0.95$ ). Numbers of galleries included (induced dispersers/delayed dispersers): gallery $(9 / 2), g_{b}(12 / 7), g_{c}(4 / 1)$ and $g_{d}(6 / 3)$. Arithmetic means of dry weight are shown with their standard errors

\section{References}

Baker JM, Norris DM (1968) A complex of fungi mutualistically involved in nutrition of ambrosia beetle Xyleborus ferrugineus. J Inv Path 11:246-250

Batra LR (1979) Insect-fungus symbiosis. Nutrition, mutualism, and commensalism. Wiley, New York

Beaver RA (1986) The taxonomy, mycangia and biology of Hypothenemus curtipennis (Schedl), the first known cryphaline ambrosia beetle (Coleoptera: Scolytidae). Ent Scand 17:131-135

Beaver RA (1989) Insect-fungus relationships in the bark and ambrosia beetles. In: Wilding N, Collins NM, Hammond PM, Webber JF (eds) Insect-fungus interactions. Academic, London, pp 121-143

Biedermann PHW (2007) Social behaviour in sib mating fungus farmers. Master thesis, University of Bern

Biedermann PHW, Klepzig KD, Taborsky M (2009) Fungus cultivation by ambrosia beetles: behavior and laboratory breeding success in three xyleborine species. Environ Entomol 38:10961105

Bischoff LL (2004) The social structure of the haplodiploid bark beetle, Xylosandrus germanus. Diploma thesis, University of Bern

Bonte D, De La Pena E (2009) Evolution of body conditiondependent dispersal in metapopulations. J Evol Biol 22:12421251

Botterweg PF (1982) Dispersal and flight behavior of the spruce bark beetle Ips typographus in relation to sex, size and fat-content. Z Angew Entomol 94:466-489
Bowler DE, Benton TG (2005) Causes and consequences of animal dispersal strategies: relating individual behaviour to spatial dynamics. Biol Rev 80:205-225

Bruintjes R, Hekman R, Taborsky M (2010) Experimental global food reduction raises resource acquisition costs of brood care helpers and reduces their helping effort. Funct Ecol 24:1054-1063

Helms Cahan S, Blumstein DT, Sundström L, Liebig J, Griffin A (2002) Social trajectories and the evolution of social behaviour. Oikos 96:206-216

Choe JC, Crespi BJ (1997) The evolution of social behaviour in insects and arachnids. Cambridge University Press, Cambridge

Costa JT (2006) The other insect societies. Belknap Press of Harvard University Press, Cambridge

Cote J, Clobert J, Fitze PS (2007) Mother-offspring competition promotes colonization success. PNAS 104:9703-9708

Craig R (1983) Subfertility and the evolution of eusociality by kin selection. J Theor Biol 100:379-397

Dahlsten DL (1982) Relationship between bark beetles and their natural enemies. In: Mitton JB, Sturgeon KB (eds) Bark beetles in North American conifers. University of Texas Press, Austin, pp $140-182$

Eden SF (1987) When do helpers help — food availability and helping in the moorhen, Gallinula-chloropus. Behav Ecol Sociobiol 21:191-195

Eichhoff W (1881) Die Europäischen Borkenkäfer. Springer, Berlin

Elkin CM, Reid ML (2005) Low energy reserves and energy allocation decisions affect reproduction by mountain pine beetles, Dendroctonus ponderosae. Funct Ecol 19:102-109

Farrell BD, Sequeira AS, O’Meara BC, Normark BB, Chung JH, Jordal BH (2001) The evolution of agriculture in beetles (Curculionidae: Scolytinae and Platypodinae). Evolution 55:2011-2027

Fischer M (1954) Untersuchungen über den kleinen Holzbohrer (Xyleborus saxeseni). Pflanzenschutzberichte 12:137-180

Francke-Grosmann H (1956) Hautdrüsen als Träger der Pilzsymbiose bei Ambrosiakäfern. Z Morph Ökol Tiere 45:275-308

Francke-Grosmann H (1975) Zur epizoischen und endozoischen Übertragung der symbiotischen Pilze des Ambrosiakäfers Xyleborus saxeseni (Coleoptera: Scolitidae). Entomologica Ger 1:279-292

French JRJ, Roeper RA (1975) Studies on the biology of the ambrosia beetle Xyleborus dispar. J Appl Entomol 78:241-247

Graham K (1961) Air-swallowing - mechanism in photic reversal of the beetle Trypodendron. Nature 191:519-520

Gyllenberg M, Kisdi E, Utz M (2008) Evolution of conditiondependent dispersal under kin competition. J Math Biol 57:285-307

Hager R, Jones CB (2009) Reproductive skew in vertebrates: proximate and ultimate causes. Cambridge University Press, Cambridge

Hamilton WD (1978) Evolution and diversity under bark. In: Mound LA, Waloff $\mathrm{N}$ (eds) Diversity of insect faunas. Blackwell, Oxford, pp 154-175

Heg D, Bachar Z, Brouwer L, Taborsky M (2004) Predation risk is an ecological constraint for helper dispersal in a cooperatively breeding cichlid. Proc R Soc Lond B 271:2367-2374

Ims RA, Hjermann DO (2001) Condition-dependent dispersal. In: Clobert J, Danchin E, Dhondt AA, Nichols JD (eds) Dispersal. Oxford University Press, Oxford, pp 203-216

Kajimura H, Hijii N (1994) Reproduction and resource utilization of the ambrosia beetle, Xylosandrus mutilatus, in-field and experiment populations. Entomol Exp Appl 71:121-132

Kalshoven LGE (1962) Note on the habits of Xyleborus destruens Bldf., the near-primary borer of teak trees on Java. Entomol Berichten 22:7-18 
Kawata M (1987) The effect of kinship on spacing among female redbacked voles, Clethrionomys rufocanus bedfordiae. Oecologia $72: 115-122$

Keller L, Reeve HK (1994) Partitioning of reproduction in animal societies. Trends Ecol Evol 9:98-102

Kingsolver JG, Norris DM (1977) The interaction of Xyleborus ferrugineus Fabr. (Coleoptera: Scolytidae) behavior and initial reproduction in relation to its symbiotic fungi. Ann Entomol Soc Am 70:1-4

Kirkendall LR, Kent DS, Raffa KF (1997) Interactions among males, females and offspring in bark and ambrosia beetles: the significance of living in tunnels for the evolution of social behavior. In: Choe JC, Crespi BJ (eds) The evolution of social behavior in insects and arachnids. Cambridge University Press, Cambridge, pp 181-215

Koenig WD, Pitelka FA, Carmen WJ, Mumme RL (1992) The evolution of delayed dispersal in cooperative breeders. Q Rev Biol 67:111-150

Kok LT, Norris DM, Chu HM (1970) Sterol metabolism as a basis for a mutualistic symbiosis. Nature 225:661-662

Kokko H, Ekman J (2002) Delayed dispersal as a route to breeding: territorial inheritance, safe havens, and ecological constraints. Am Nat 160:468-484

Korb J, Heinze J (2008) The ecology of social life: a synthesis. In: Korb J, Heinze J (eds) Ecology of social evolution. Springer, Berlin, pp 245-259

Krausseopatz B, Kohler U, Schopf R (1995) The energetic state of Ips typographus L. (Coleoptera, Scolytidae) during the life-cycle. Z Angew Entomol 119:185-194

Liang KY, Zeger SL (1986) Longitudinal data-analysis using generalized linear-models. Biometrika 73:13-22

Latty TM, Reid ML (2010) Who goes first? Condition and danger dependent pioneering in a group-living bark beetle (Dendroctonus ponderosae). Behav Ecol Sociobiol 64:639-646

McNee WR, Wood DL, Storer AJ (2000) Pre-emergence feeding in bark beetles (Coleoptera: Scolytidae). Environ Entomol 29:495501

Milne DH, Giese RL (1970) Biology of the Columbian timber beetle, Corthylus columbianus (Coleoptera: Scolytidae). 10. Comparison of yearly mortality and dispersal losses with population densities. Entomol News 81:12-24

Moore JC, Loggenberg A, Greeff JM (2006) Kin competition promotes dispersal in a male pollinating fig wasp. Biol Lett 2:17-19

Mueller UG, Gerardo NM, Aanen DK, Six DL, Schultz TR (2005) The evolution of agriculture in insects. Ann Rev Ecol Evol Syst 36:563-595
Norusis M (2007) Generalized estimating equations. In: Norusis M (ed) SPSS 15.0 advanced statistical procedures companion. Prentice Hall, Upper Saddle River, pp 279-296

Peer K, Taborsky M (2004) Female ambrosia beetles adjust their offspring sex ratio according to outbreeding opportunities for their sons. J Evol Biol 17:257-264

Peer K, Taborsky M (2005) Outbreeding depression, but no inbreeding depression in haplodiploid ambrosia beetles with regular sibling mating. Evolution 59:317-323

Peer K, Taborsky M (2007) Delayed dispersal as a potential route to cooperative breeding in ambrosia beetles. Behav Ecol Sociobiol 61:729-739

R Development Core Team (2008) R: a language and environment for statistical computing. R Foundation for Statistical Computing, Vienna

Reid RW (1958) The behaviour of the mountain pine beetle, Dendroctonus monticolae Hopk., during mating, egg laying, and gallery construction. Can Entomol 90:505-509

Roeper R, Treeful LM, O'Brien KM, Foote RA, Bunce MA (1980) Life history of the ambrosia beetle Xyleborus affinis (Coleoptera: Scolytidae) from in vitro culture. Great Lakes Entomol 13:141-144

Roisin Y (1994) Intragroup conflicts and the evolution of sterile castes in termites. Am Nat 143:751-765

Schedl KE (1956) Breeding habits of arboricole insects in Central Africa. Verh 10 Int Kongr Entomol (Vienna) 1:183-197

Schneider I (1987) Distribution, fungus-transfer and gallery construction of the ambrosia beetle Xyleborus affinis in comparison with $X$. mascarensis (Coleoptera, Scolytidae). Entomologia Generalis 12:267-275

Stacey PB, Koenig WD (1990) Cooperative breeding in birds: longterm studies of ecology and behavior. Cambridge University Press, Cambridge

Stacey PB, Ligon JD (1991) The benefits-of-philopatry hypothesis for the evolution of cooperative breeding: variation in territory quality and group size effects. Am Nat 117:831-846

Sundstrom L (1995) Dispersal polymorphism and physiological condition of males and females in the ant, Formica truncorum. Behav Ecol 6:132-139

West-Eberhard MJ (1975) The evolution of social behaviour by kin selection. Q Rev Biol 50:1-33

Whitney HS (1971) Association of Dendroctonus ponderosae with blue stain fungi and yeasts during brood development in lodgepole pine. Can Entomol 103:1495-1503

Zeger SL, Liang KY (1986) Longitudinal data-analysis for discrete and continuous outcomes. Biometrics 42:121-130

Zera AJ, Denno RF (1997) Physiology and ecology of dispersal polymorphism in insects. Ann Rev Entomol 42:207-230 